III ENEI

Encontro Nacional de

Economia Industrial e Inovação
Indústria e Desenvolvimento Econômico:

desafios e perspectivas

18 a 20 de setembro de 2018

Uberlândia - Minas Gerais

\title{
POLÍTICA SALARIAL E DESENVOLVIMENTISMO: UMA ANÁLISE DOS IMPACTOS NOS SALÁRIOS DA INDÚSTRIA E NO CONFLITO DISTRIBUTIVO
}

Matheus Rissa Peroni Ribeiro ${ }^{1}$

Luiz Gustavo Fernandes Sereno ${ }^{2}$

\section{RESUMO:}

O trabalho visa a investigar os desdobramentos dos recentes aumentos reais do salário mínimo nos custos da indústria brasileira a partir da divergência em torno do tema da literatura desenvolvimentista. Busca mostrar que o crescimento real experimentado pelo salário mínimo não altera fundamentalmente a determinação do salário na indústria brasileira, assim como não é possível afirmar que causa aumento na participação dos salários industriais no lucro. Além de tudo, com o crescimento do Valor Agregado da indústria e das taxas de lucros verificados, é plausível supor efeitos positivos para a intensificação industrial.

Palavras-chave: salário mínimo, salário industrial, desenvolvimentismo, conflito distributivo.

\begin{abstract}
:
This paper aims to inquire about the unfolding of the recent real increases of the Brazilian minimum wage in industry total costs from the divergence of the developmentalist economic literature. It attempts to show that the minimum wage real growth does not fundamentally alters the wage determination in Brazilian industry, as it is not possible to say that it raise the industrial wage quota on industrial earnings. Besides, with the seen growth of the industry added value and profit rates, it is plausible to assume positive effects on industrial intensification.

Key words: minimum wage, industrial wage, developmentalism, distributive conflict.
\end{abstract}

Área ABEIN: Área 1.7 Indústria e políticas macroeconômicas

Classificação JEL: J31, J38

\section{INTRODUÇÃO}

A política pública de valorização do salário mínimo como instrumento adicional para a redução da desigualdade da distribuição pessoal da renda que se tornou uma política continua, de fato, nos governos Lula (2003 - 2010) e Dilma (2011-2014), conduziu o Brasil a um modelo de crescimento liderado pelo consumo (wage-led). Em outras palavras, seria uma estratégia de desenvolvimento apoiada na expansão do mercado interno, no qual o crescimento robusto dos salários em termos reais gera uma forte expansão dos gastos de consumo, o que, por sua vez, poderia induzir um aumento do investimento.

Não obstante, parte do debate acadêmico e político consideram o modelo de crescimento wage-led insustentável no longo prazo, pois um contínuo crescimento real da participação dos salários na renda conduz a uma queda da taxa de lucro, gerando um conflito distributivo em detrimento do lucro, agravando a expectativa do empresário em relação a novos investimentos. Além disso, argumenta-se que tal política, aumenta a tendência de apreciação da taxa real de câmbio, provocando assim uma transferência de atividades produtivas para o exterior, e consequentemente, a um processo de desindustrialização.

Considerando tais interpretações, este trabalho possui o objetivo de investigar os impactos da política de aumentos reais do salário mínimo no custo salarial do setor industrial. Em virtude disso,

\footnotetext{
${ }^{1}$ Mestrando em Economia - PPGE UFU matehusperoni@ufu.br

${ }^{2}$ Mestrando em Economia - PPGE UFU 1gsereno@ufu.br
} 
além dessa introdução, este texto está divido em quatro seções além desta introdução. Na primeira, é feito um resgate do debate teórico-político acerca das visões desenvolvimentistas no Brasil, bem como a divergência dessas com relação a política de aumento salarial. Na segunda, procura-se explorar brevemente a influência do salário mínimo nas taxas salariais e nos preços. Na terceira seção, é realizada uma análise empírica descritiva a respeito da relação entre o crescimento do salário mínimo real e sua influência nos salários e custos da indústria, ademais investiga-se o conflito distributivo entre lucros e salários industriais. Por fim, na quarta seção, são apresentadas as considerações finais do trabalho.

\section{O DEBATE DESENVOLVIMENTISTA E A DIVERGÊNCIA EM RELAÇÃO A POLÍTICA SALARIAL}

No período recente, compreendido pelos dois governos Lula e início do governo Dilma, mais especificamente entre os anos de 2004 e 2014, o Brasil obteve resultados favoráveis no plano macroeconômico e social. Neste interregno foi observada taxas mais robustas de crescimento do produto, acompanhada de níveis de preços controlados (o Índice de Preços ao Consumidor - IPCA esteve a baixo do teto da meta, e três anos de taxas de inflação abaixo do centro da meta, no período indicado), além de ocorrer grandes acúmulos de reservas internacionais e redução da relação dívida pública/PIB, gerando uma consequente diminuição da vulnerabilidade externa do país. Já no âmbito social, a taxa de desemprego diminuiu progressivamente, junto com políticas de expansão do crédito, de ampliação dos gastos sociais e de aumentos reais do salário mínimo, reduziram a pobreza total e provocaram uma pequena melhora na distribuição de renda. Tudo isso foi constituído a partir do boom de commodities a partir de 2003, e posteriormente, iniciado em 2006, uma ampliação do mercado interno, determinante essencial para o crescimento econômico e social (FILGUEIRAS, 2012).

Esse momento de bonança da economia brasileira, suscitou o retorno do debate teóricopolítico com relação ao processo de desenvolvimento do país. Entre as diversas visões iremos apresentar as diferentes perspectivas entre o chamado Novo-Desenvolvimentismo (Precursores e Póskeynesianos) e o Social-Desenvolvimentismo, acerca da importância relativa entre o mercado interno e o setor externo como condutor do desenvolvimento, e o reconhecimento de diferentes variáveis 'chaves' de demanda que puxam o crescimento da economia brasileira. Tais perspectivas e propostas são consideradas por terem raízes estruturalistas e são mencionadas como 'desenvolvimentistas' pois preconizam o esforço deliberado em promover o estímulo ao crescimento concomitante à ampliação do emprego e da renda. Além disso, trataremos com mais cuidado sobre a divergência com relação a política salarial entre duas dessas visões, com o intuito de resgatar o debate e contextualiza-lo com a análise aqui realizada.

Os Novo-Desenvolvimentistas, segundo Sicsú et al (2005), possuem diversas influências entre as quais a visão de Keynes de complementariedade entre o Estado e o mercado e a visão cepalina estruturalista cuja preocupação se refere à transformação produtiva com equidade. Dessa forma o projeto novo-desenvolvimentista não objetiva defender o projeto de centralização econômica, com um Estado forte; nem o extremo oposto, o qual defende o mercado como condutor da economia e um Estado fraco. No entanto, entre esses dois extremos existe a possibilidade de constituir "um Estado forte que estimula o florescimento de um mercado forte" (SICSÚ ET AL, 2005, p. 01).

Nessa perspectiva, os novos-desenvolvimentistas precursores, iniciada por Bresser-Pereira (2004, 2007, 2010), compreende a visão de que o mercado externo, a partir do aumento das exportações liquidas, é o fator que proporcionará o desenvolvimento brasileiro. Dessa forma, o autor considera primordial elevar a taxa de investimento na economia além de orientar a economia para as exportações, condicionada por uma taxa de juros menor do que os patamares observadores e a existência de uma taxa de câmbio competitiva. No entanto, o autor assume que a "variável-chave da política de desenvolvimento deve ser a taxa de câmbio" (Bresser-Pereira, 2010, p. 669). Acrescenta que tal variável possui uma tendência estrutural de sobrevalorização, causando um desalinhamento entre a taxa de câmbio de equilíbrio corrente e a taxa de câmbio de equilíbrio industrial, a qual é necessária para manter o crescimento. Julga ser essa apreciação estrutural do cambio a responsável 
pelo processo de desindustrialização precoce no Brasil. Segundo o autor, a fonte da apreciação cambial se localiza no resultado das transações correntes, assim a industrialização deve ser norteada para as exportações, o que necessita de uma depreciação da moeda doméstica para garantir condições para equilibrar o setor industrial, levando ao modelo conduzido pelas exportações (export-led). Porém, para o autor isso seria "apenas transitoriamente, uma vez que para haver desenvolvimento é preciso aumentar salários e PIB per capita, ampliando, consequentemente, o mercado interno", ressalta Mollo e Fonseca (2013, p. 235)

Diferentemente do Bresser-Pereira, o qual identifica que o problema que desequilibra a economia é fruto da performance das transações correntes, Sicsú et al (2005) defendem que a dificuldade se encontra na conta de capitais. Além dessa diferença, os novo-desenvolvimentistas pós-keynesianos, como o próprio nome diz, possui uma influência da teoria pós-keynesiana mais evidente. Esse grupo, embora também deem importância para o mercado externo, a preocupação central torna-se evitar a vulnerabilidade externa em que o país incorre devido às entradas e saídas de capitais, por vezes essencialmente especulativos. Nesse sentido, segundo Mollo e Fonseca, a

"variável-chave não seria a taxa de câmbio, mas a de juros, cuja queda, ao evitar entrada de capitais especulativos, impediria a apreciação cambial e beneficiaria não apenas as exportações, mas o fortalecimento do mercado interno. $\mathrm{O}$ desenvolvimento do mercado interno, além do das exportações, permite avançar na questão redistributiva, ao ampliar as oportunidades de emprego e salário" (MOLLO E FONSECA, 2013, p. 236).

Além da necessidade de adoção de medidas que visem a diminuição da volatilidade intensa da taxa de câmbio e, concomitantemente, trabalhar com uma taxa de câmbio atraente e competitiva para estimular as exportações, os novos-desenvolvimentistas (precursores e pós-keynesianos) chamam atenção da indispensabilidade de que se tenha equilíbrio fiscal. Porém, não se trata de uma política fiscal restritiva com objetivos simplistas de superávit fiscal, mas sim de separar os gastos correntes do governo dos gastos em investimento. Em outras palavras, Keynes, separa o orçamento do governo em dois, conseguindo dessa forma mostrar a conveniência de se realizar políticas fiscais ativas que estimulem o investimento, sem incorrer no comprometimento das finanças estatais. Assim sendo, os gastos correntes do governo necessitariam de equilíbrio ou superávits circunstanciais e o os gastos em investimentos deveriam ser ativos e harmoniosos com os resultados do orçamente corrente (SICSÚ ET AL, 2005).

A corrente denominada social-desenvolvimentista, por sua vez, destacam as políticas de redistribuição de renda e aumento real dos salários, e dessa forma tendo como força motora do desenvolvimento o mercado interno. Segundo Mollo e Amado (2015), tais preocupações levam essa abordagem a dialogar também com a tradição marxista. No entanto, segundo a mesma autora, parte do posicionamento marxista defende o desenvolvimentismo-distributivo, a partir da "ideia de autonomia relativa do Estado com relação às classes que permite esperar que se possa contar com o Estado e suas políticas para melhorar a condição dos trabalhadores ou sua posição na relação capitaltrabalho" (p. 15). Para esse grupo, a justificativa de tal posicionamento, expressa que as políticas de redistribuição de renda e aumento real dos salários podem garantir maior número de empregos, e consequentemente, maior poder de barganha do trabalhador e se inserindo o assalariado em uma posição melhor na relação capital-trabalho. A outra posição Marxista, "critica essa defesa na base da ideia de que não é possível contar com o Estado capitalista para transformar a sociedade, mas penas com a luta de classes" (p. 15).

Nessa proposta observa-se certa prudência com relação a taxas de câmbio competitivas, devido ao fato de que a desvalorização da moeda tem efeitos inflacionários que diminuem os salários reais. Portanto para o social-desenvolvimentismo a variável-chave é o consumo, chamado de modelo wage-led, o qual diante da oportunidade de se ter uma dimensão potencial de mercado interno grande, a produção e o consumo de massa possibilitam aumentar os rendimentos gerados por elevação da produtividade com economias de escala, além de potencializar a elevação dos salários. Assim, 
segundo os autores do social desenvolvimentismo, o mercado interno como mola impulsionadora do desenvolvimento gera mais garantias de distribuição de renda e de aumento das rendas das classes mais baixas, o que não teria o resultado esperado a partir do crescimento movido pelo setor externo.

Essa questão de competitividade externa e desenvolvimento do mercado interno, e as visões referentes ao conflito distributivo entre salários e lucros, suscitaram discussão semelhante sobre qual é a estratégia mais adequada para o desenvolvimento, porém em uma dicotomia entre o wage-led e o profit-led (segundo Takasago, Mollo e Guilhoto (2017), o profit-led se associa aos defensores do modelo export-led). Tal debate parte da ideia de que ao aumentar os salários o consumo incentiva o aumento da capacidade instalada a partir do aumento das vendas e, consequentemente, se eleva o investimento, o crescimento e o emprego. Por outro lado, a elevação dos salários impacta negativamente as margens de lucro, pela ótica dos custos, afetando a lucratividade das empresas e, consequentemente, restringindo o aumento do investimento e do produto. Porém, Santos (2013), ao tentar escapar de tal paradoxo, apoia-se na ideia de que a melhor estratégia para o desenvolvimento deixa de ser uma opção entre o crescimento via wage-led ou profit-led, mas um crescimento liderado pelo investimento. Segundo o autor, o aumento do investimento leva ao crescimento da produção, ampliando a quantidade de emprego e elevando a massa de salários, e, por conseguinte, o aumento das vendas e do consumo. Ademais, o autor indica que as consequências das políticas salariais sobre os níveis de produto são confusas e possuem efeitos distintos em diferentes níveis de desenvolvimento.

Apresentadas as visões mais gerais das três perspectivas de desenvolvimento, torna-se necessário para dar prosseguimento a análise do presente trabalho, as diferentes visões com relação a política salarial. No âmbito desse debate, a visão dos novos-desenvolvimentistas precursores possui uma perspectiva totalmente diferente da percepção social desenvolvimentista quanto a variável 'taxa de salário'.

Como já mencionado, segundo Bresser (2016), os novos-desenvolvimentistas precursores consideram que a taxa de câmbio dos países em desenvolvimento, sobretudo aqueles afetados pela doença holandesa, recorrentemente são sobrevalorizadas no longo prazo. Diante dessa característica, a elasticidade renda das exportações será diminuída e a elasticidade renda das importações será aumentada. Em outras palavras, a competitividade das empresas nacionais será reduzida, diminuindo a taxa de lucro esperada e a disposição para o investimento, enquanto os salários reais serão artificialmente elevados. Em face a esse conflito distributivo, Bresser enfatiza:

"se o crescimento depende dos investimentos das empresas, os formuladores de políticas devem trabalhar por um meio-termo entre os empresários e os trabalhadores, entre uma taxa de lucro satisfatória e salários que aumentem com a produtividade.” (BRESSER-PEREIRA, 2016, p. 247)

Especificamente para Oreiro (2012), é necessário promover uma moderação salarial, sendo até bem vindo a indicação de reduções salariais ex-ante (independente da redução salarial ex-post advinda da desvalorização cambial), para garantir uma taxa cambial que gere competitividade às exportações. O autor afirma que "um regime de crescimento wage-led é insustentável a longo prazo", porque "um aumento cumulativo da participação dos salários na renda irá resultar, em algum momento, em uma tendência a queda da taxa de lucro", e assim, gerando um conflito distributivo na sociedade. (OREIRO, 2012, p. 32). Nesse sentido, o modelo wage-led gera um aumento sucessivo da participação do consumo no produto e elevação dos custos do trabalho, conduzindo a uma perda de competitividade externa da economia. Dessa forma, o autor argumenta que o modelo wage-led é representado por quedas contínuas do coeficiente de exportações, desequilíbrio no balanço de pagamentos, desindustrialização e re-primarização da pauta exportadora.

Bielschowsky (2012), de maneira oposta, ao defender o social-desenvolvimentismo, expõe que as decisões de investir das empresas brasileiras são orientadas pelo mercado interno, uma vez que, as exportações operam como complemento à demanda externa. Dessa forma, o consumo de massa, além do investimento em infraestrutura e dos recursos naturais abundantes, torna-se o 'motor' 
de maior relevância para desenvolvimento econômico, permitindo ampliar os rendimentos de escala, o progresso técnico e os salários no Brasil.

Portanto, a interpretação social-desenvolvimentista, visão a qual Mollo e Amado (2015) assume a ser a posição de sua concordância, parte do princípio de que independente dos modelos serem via investimento ou por consumo de massa, o importante é realizar estimo ao mercado interno. Pois mesmo que seja provocado pelo consumo, tal fato não inibiria o investimento vis-à-vis aumento de salários, "como pensam os desenvolvimentistas precursores, porque o que aumenta com o consumo é a fatia de lucros, influindo positivamente na decisão de investir" (MOLLO E AMADO, 2015, p. 22). Portanto, como nas outras visões, o lado da demanda é de suma importância e precisa ser priorizado, seja para adequar as estruturas produtivas frente as especificidades de novos paradigmas tecnológicos, seja para ampliar a capacidade produtiva, o emprego e os salários sem pressão na taxa de inflação. No entanto, Mollo e Amado coloca-se do lado dos desenvolvimentistas sociais devido,

“em particular pela melhor inserção dos trabalhadores na relação capitaltrabalho que propicia, ampliando seu poder de barganha nas negociações salariais e viabilizando maior poder de organização para ganhos maiores." (MOLLO E AMADO, 2015, p. 23)

Em vista dessas diferentes interpretações de qual o modelo mais adequado para promover o desenvolvimento do Brasil, e principalmente, das divergências quanto o papel dos salários no avanço da economia, torna-se necessário dar avanço ao debate. Para isso, o presente trabalho irá afunilar a ferramenta de trabalho, pois como foi apresentado, a variável 'taxa de crescimento do salário' tornase se um importante fator para a competitividade e distribuição de renda na economia. Devido a esses motivos, buscaremos nos próximos dois itens, identificar quais os fatores que influenciam o aumento do salário médio da economia, tanto quanto dos setores de serviços e industriais, procurando identificar a relação entre o crescimento do salário mínimo real e sua influência nos salários e custos da indústria.

\section{SALÁRIO MINIMO E SUA INFLUÊNCIA SOBRE A TAXA SALARIAL E OS PREÇOS}

A política de valorização real do salário mínimo foi implementada em 2003, a partir do primeiro governo Lula, e institucionalizada em 2007, tornou explícito o propósito de elevar o poder de compra dos trabalhadores de menor renda. Mais especificamente, em 2011 foi aprovada a lei 12.382 que fixou a regra para os reajustes anuais do salário mínimo, a qual passou a conceder o reajuste de acordo com a inflação (INPC) de um ano anterior somada ao resultado do crescimento do PIB de dois anos passados. No entanto, no biênio 2017-2018, em um ambiente de recessão e estagnação econômica, a política de reajusteis reais do salário mínimo foi interrompida, em 2017 foi realizado reajuste de $6,48 \%$, ante um INPC de $6,58 \%$, e em 2018 foi reajustado em 1,81\% para um INPC de 2,07\% (DIEESE, 2018).

O salário mínimo pode ser considerado como a taxa de salários base da economia. A definição de um salário mínimo institucional é um piso correspondente a um nível de consumo considerado socialmente necessário para o trabalhador e sua família realizarem a manutenção de suas vidas. Dessa forma, o salário mínimo formaliza o poder de barganha dos trabalhadores, tornando-o, sobretudo, um salário político (MEDEIROS, 2015). O nível geral de salários, assim como o valor do salário mínimo, são variáveis de grande importância para a economia pois mudanças em seu valor tendem a se propagar e seus impactos afetam variáveis econômicas. A respeito disso, esse item tem o objetivo de abordar brevemente a influência do salário mínimo sobre as taxas de salários, os preços e, consequentemente, a condução da política monetária.

Considerando o elevado nível de heterogeneidade na estrutura produtiva e social como a brasileira, a relação entre salário mínimo, taxa de salários e renda do trabalho autônomo estabelece um ponto relevante a respeito do conflito distributivo das rendas. Por conseguinte, a política salarial 
pode ter influências distintas sobre os diversos setores econômicos, assim como impactos na renda de trabalhadores de diferentes níveis salariais, sejam estes do setor formal ou informal da economia. (MEDEIROS, 2015)

Entretanto, a hipótese de que o salário mínimo se constituiu como a taxa de salário base da totalidade do mercado de trabalho necessita de uma avaliação do nível de influência na formação dos salários e rendas nas diversas atividades. O efeito do aumento do salário mínimo sobre os salários pode ser obtido pela diferença relativa do salário médio em relação ao salário mínimo, ou seja, quanto mais distante o rendimento do salário mínimo menor a tendência de aumento proporcional. Decorre também, segundo SUMMA (2014), do poder de barganha do trabalhador, que tem como fator determinante a situação estrutural e conjuntural do mercado de trabalho somado a fatores políticos e institucionais.

Com o intuito de demonstrar a dispersão salarial realizou-se no Gráfico 1, com índice de base 100, a comparação entre a evolução do comportamento do salário mínimo e do salário médio entre os anos 2000 e 2015. A partir deste, é possível observar que o aumento do salário real médio não acompanha o ritmo de crescimento do salário mínimo real, corroborando a concepção de que o nível do impacto da valorização do salário mínimo nas taxas de salários é disperso e heterogêneo.

Ademais, segundo Medeiros (2015), o salário mínimo possui um 'efeito farol' nos salários de setores informais, isto é, o salário mínimo é tomado como referência central para a determinação de tais salários. De forma distinta, o salário do trabalhador autônomo é balizado conforme a situação da demanda e do número de ofertantes desses bens e serviços. Nesse sentido, o salário mínimo age tanto por meio do seu impacto sobre a demanda, quanto por meio da redução de trabalhadores ocupados nessas atividades.

Em relação ao impacto do salário mínimo sobre os preços é preciso considerar que, diante de uma economia com alto grau de heterogeneidade, a influência sobre os custos da folha salarial entre os setores produtivos é muito distinta, a qual depende do nível de aumento da produtividade e dos preços relativos. Isto é, um aumento do salário base pode refletir em aumento dos preços conforme maior ou menor pressão sobre os custos médios da força de trabalho e o grau de mark-up das empresas. Dessa forma, a empresa absorve tal aumento por uma redução na parcela dos lucros ou por um crescimento menor dos salários mais altos, influenciando a dispersão salarial. (MEDEIROS, 2015)

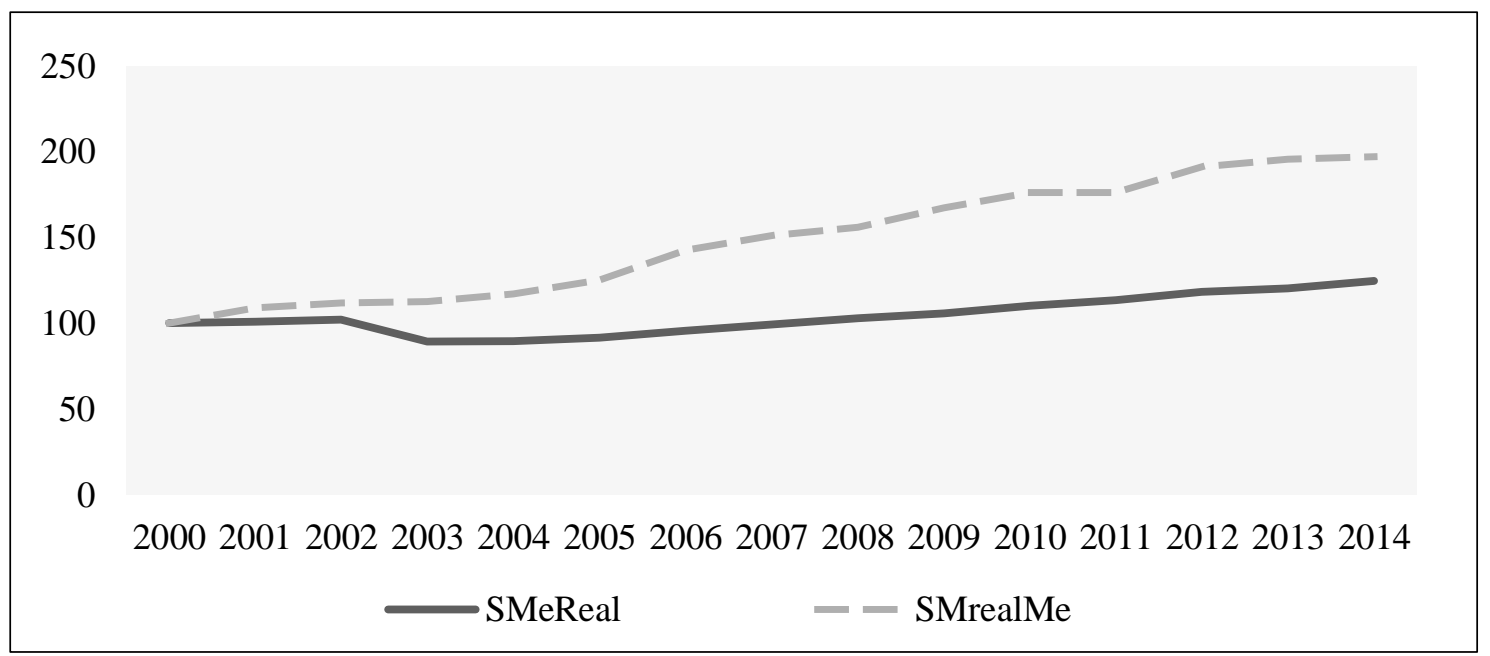

GRÁFICO 1 - Evolução do Salário Médio Real da Economia (SMeR) e do Salário Mínimo Real Médio (SMrealMe), anual, de 2000 a 2014 (Ano base = 2000)

Fonte: Elaboração própria a partir de dados do Ipeadata (2017)

Nessa perspectiva, o salário representa um custo para a firma, então se espera que um reajuste do salário mínimo possua maior efeito em setores mais intensivos em trabalho do que setores mais intensivos em capital, ou seja, setores de serviços, comércio e transporte possuem maior impacto nos custos do que os setores industriais e agropecuários. 
Segundo Martinez e Braga (2012), o impacto da correção do salário mínimo sobre a inflação é difícil ser constatado devido ao fato do reajuste se concentrar em apenas um mês do ano. Porém, algumas evidências indicam que o salário mínimo foi importante para explicar a evolução dos preços de alguns setores.

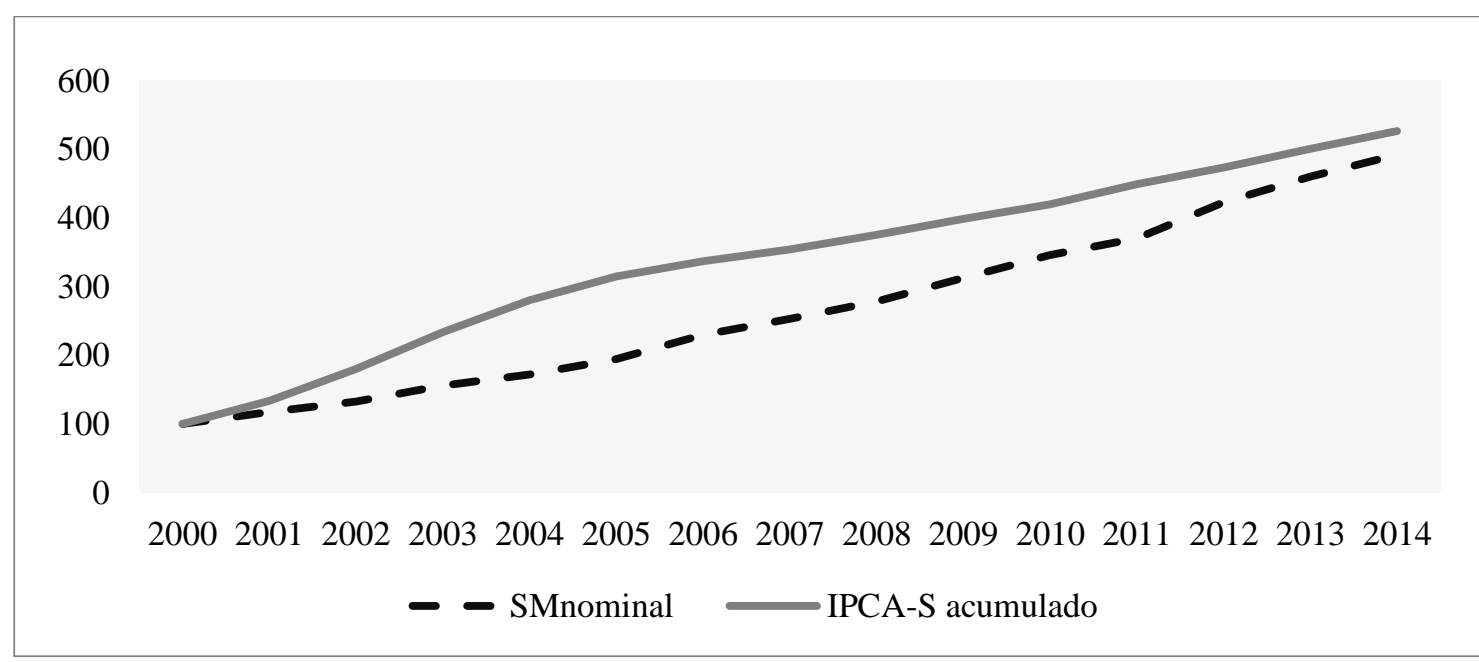

GRÁfICO 2- Evolução do Salário Mínimo Nominal (SMnominal) e da Inflação de serviços acumulada (IPCA-S), anual, de 2000 à 2014 (Ano base = 2000)

Fonte: Elaboração própria a partir de dados de Ipeadata (2017)

Para ilustrar essa influência, é apresentada no Gráfico 2 a relação entre a trajetória do salário mínimo nominal e a inflação do setor de serviços - medida pelos componentes de transportes; saúde e cuidados pessoais; despesas pessoais; educação e comunicação - do IPCA - acumulada entre os anos de 2000 e 2014. O Gráfico 2 evidencia que as duas séries lograram tendência semelhante de crescimento, constatando o fato de que o crescimento do salário mínimo possui influencia na determinação dos preços do setor de serviços.

Em vista disso, pode-se afirmar existência na interação entre o salário mínimo e preços, mostrando até aqui que essa influência possui, sobretudo, impacto na determinação dos preços livres que estão relacionados à prestação de serviços. Acrescentando ainda o fato de que o setor de serviços nos últimos anos vem aumentando sua participação no produto da economia brasileira, em detrimento da participação da indústria (FIESP, 2015). Considera-se a política de valorização do salário mínimo um fator importante na determinação da taxa de inflação brasileira.

Nessa perspectiva, o salário mínimo passa a ser um elemento de influência na condução da política monetária brasileira. Segundo Martinez e Braga (2012), a indexação do salário mínimo ao crescimento e à inflação gera uma reação da política monetária para conter possíveis instabilidades. Isto é, tudo mais constante, a política monetária torna-se mais restritiva do que seria sem a regra de indexação do salário mínimo. Tomando esse pressuposto como válido, o efeito da política de valorização do salário mínimo tenciona o Banco Central do Brasil em priorizar o comportamento da inflação, deixando em segundo plano o crescimento. Em outras palavras, a reação da política monetária torna-se mais orientada no alcance da meta de inflação do que na meta de crescimento do produto.

A existência de influência do aumento do salário mínimo nas taxas de salários, nos preços e na condução da política monetária e suas consequências possuem também efeito nos custos industriais. Para isso, o próximo item procura explorar qual impacto do valor do salário mínimo no custo dos salários no setor industrial.

\section{IMPACTOS DO SALÁRIO MÍNIMO NA INDÚSTRIA}

Tendo em consideração a necessidade de se entender a influência dos aumentos cíclicos do salário mínimo sobre o custo da indústria, primeiramente há de se investigar a relação entre salário mínimo e o salário da indústria. Para tanto, em um primeiro momento, compararemos a evolução do 
salário mínimo real e a evolução do salário médio real das indústrias de São Paulo. Ambos os dados foram extraídos da base de dados do Instituto de Pesquisa Econômica Aplicada ${ }^{3}$ (IPEADATA). Além do índice de Salário Real Médio da Indústria de São Paulo, calculou-se o salário real médio da indústria brasileira pela razão entre Salários e o Pessoal Ocupado (PO) em 31 de dezembro de cada ano, mantendo-se constante a cada mês do ano. Foi ainda calculado o índice de produtividade industrial como razão entre o Valor Agregado Bruto (VAB) da indústria e o PO, também constante em todos os meses de cada ano. Os dados de VAB, PO e Salários foram extraídos da Pesquisa Industrial Anual ${ }^{4}$ (PIA-EMPRESA) do Instituto Brasileira de Economia e Estatística (IBGE). Os valores de VAB e Salários foram ainda deflacionados pelo Índice Preços ao Consumidor Ampliado (IPCA) do IBGE obtido também junto ao IPEADATA.

Como nos interessam as trajetórias assumidas pelas variáveis ao longo do tempo, e não seu valor absoluto, continuaremos a utilizar a ferramenta de índice para a análise das variáveis. Neste caso, a base escolhida foi maio de 1996, correspondente à primeira observação da amostra na qual houve reajuste do salário mínimo nominal no período. Em relação aos dados de salário, por se tratarem de observações mensais, a amostra capta a influência da inflação mensal e, portanto, optouse pela interpretação acerca da média móvel em 12 meses. Por fim, o recorte temporal escolhido foi entre os anos de 1995 e $2016^{5}$, considerando que no período existiram políticas razoavelmente distintas de aumento do salário mínimo institucional ${ }^{6}$. Sobretudo aumento brando no governo de Fernando Henrique Cardoso e acréscimos reais consecutivos durante os governos de Lula e Dilma Rousseff.

A relação entre salário mínimo e salário da indústria (Gráfico 3) era relativamente estável entre os anos de 1995 e 1999: o salário mínimo e o salário da indústria apresentam curvas quase paralelas com taxas de crescimento de 2,94\%3,39\% ao ano. A partir de 1999, no entanto, nota-se certo descolamento entre salário mínimo e salário da indústria de SP, sucessivamente intensificado até 2016. Podemos considerar que tal deslocamento é passível ser divido em três períodos com intensidades distintas.

Inicialmente, entre os anos de 1999 e 2003, o salário mínimo real e o salário médio real da indústria passam a apresentar trajetórias contrárias. Enquanto o salário mínimo real apresenta crescimento médio anual de 3,29\%, o salário da indústria experimenta redução em seu valor real na ordem de $0,43 \%$ ao ano. Para o entendimento desse início do descolamento ressalta-se além da queda do salário real da indústria, o crescimento do Salário Mínimo real em 2001 (9,08\%). Nesse período, a razão entre salário da indústria de SP e salário mínimo que era 1 em 1996 e 1,01 em 1999 passa para 0,86 em 2003.

O segundo período - entre os anos de 2004 e 2007 - é dado por um salto no salário mínimo real brasileiro enquanto salário médio da indústria experimenta uma retomada do crescimento real. Dessa forma, o salário médio real da indústria cresce a 3,33\% ao ano, ainda inferior ao crescimento do salário mínimo, o qual aumentou no período a uma taxa anual de $8,96 \%$ ao ano. Tal disparidade no crescimento faz com que a razão entre salário médio da indústria de SP e salário mínimo caia de 0,86 em 2004 para 0,74 em 2007.

\footnotetext{
${ }^{3}$ http://www.ipeadata.gov.br/

${ }^{4} \mathrm{https} / / /$ www.ibge.gov.br/estatisticas-novoportal/economicas/industria/9042-pesquisa-industrial-anual.html

${ }^{5}$ Para o cálculo da produtividade só estão disponíveis dados entre 1996 e 2015

${ }^{6}$ Para uma discussão mais ampla acerca do salário mínimo institucional no Brasil, ver SCHLABITZ (2014)
} 


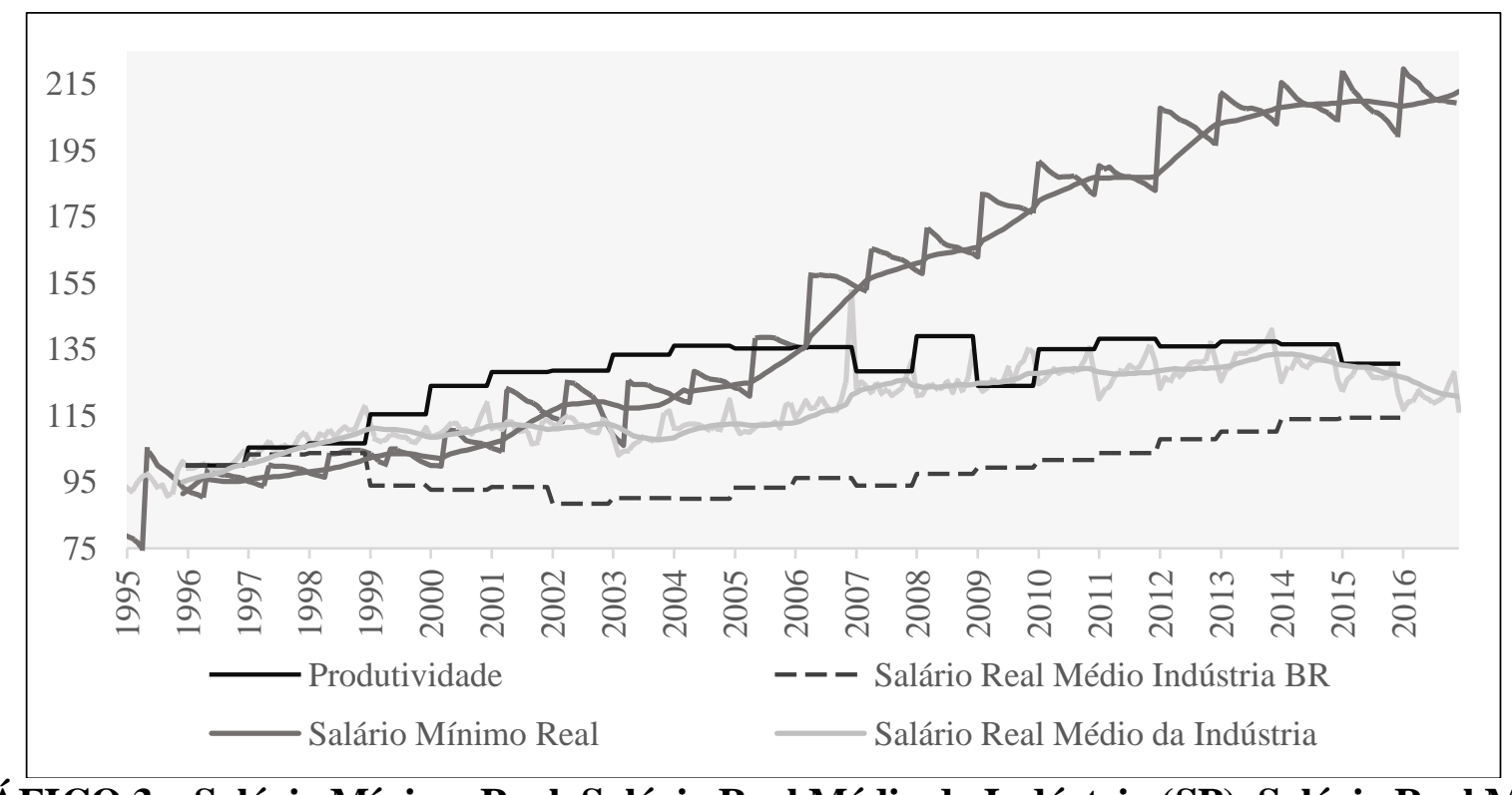

GRÁFICO 3 - Salário Mínimo Real, Salário Real Médio da Indústria (SP), Salário Real Médio da Indústria BR e Produtividade da Industria, mensal, de janeiro de 1995 a dezembro de 2016 (Mai/96=100)

Fonte: Elaboração própria a partir de dados do Ipeadata (2017) e IBGE-PIA (vários anos)

A partir de 2008, no entanto, verifica-se no salário médio da indústria uma redução média anual de $0,31 \%$ ao passo que o salário mínimo aumenta a uma taxa média de $3,18 \%$ ao ano, caracterizando o terceiro período. Com efeito, nesse momento intensifica-se o grau do descolamento entre salário mínimo e salário da indústria, notando que ao final de 2016 a razão entre salário da indústria de SP e salário mínimo real é de 0,54. Induz-se, portanto, que a diferença que passa a existir entre o nível do salário mínimo real e o salário real da indústria é resultado do aumento institucional do salário mínimo vis-à-vis a determinação do salário real industrial, dado que em toda a série o salário mínimo real cresce a uma taxa média anual de 4,20\% contra 1,26\% do salário da indústria de SP e $0,71 \%$ do salário da indústria total.

Tendo isto em vista, os três períodos distintos apresentados no Gráfico 3 demonstram não ser possível inferir sobre a relação direta dos aumentos reais constantes no salário mínimo na definição do salário real médio da indústria. Por outra via, o aumento do salário real da indústria verificado entre 2004 e 2007, poderia ser explicado pelo intenso aumento na produtividade entre 1999 e 2004, valendo-se da prerrogativa do atraso existente entre aumento de produtividade e seu impacto no salário real. Argumento que pode ser corroborado pelo menor crescimento da produtividade entre os anos de 2005 e 2009 e sua consequente quase estagnação do salário real da indústria a partir de 2007.

A menor taxa de crescimento do salário da indústria total se deve, sobretudo, às quedas bruscas experimentadas nos anos de 1999 e 2002 que levaram o salário médio industrial a uma queda anual de $2,02 \%$ entre 1996 e 2002. A partir de 2003, no entanto, a trajetória de crescimento foi quase constante: em 2010 ele supera, pela primeira vez na série o valor de 1996 e entre 2002 e 2015 cresce a uma taxa média anual de $2,00 \%$.

É importante notar, ainda, que os aumentos consecutivos na produtividade entre 1999 e 2004 estão associados a quedas no salário real industrial total. Nesse período a correlação entre produtividade e salário industrial brasileiro foi de -0,88: dessa forma, para um mesmo número de trabalhadores o valor produzido aumentou e os salários diminuíram. A partir de 2005, no entanto, os aumentos consecutivos no salário real médio industrial não parecem, necessariamente, guardar relação com a estagnação da produtividade, dado que a correlação dos índices no período total foi de 0,03. Por fim nota-se na Tabela 1 que, em geral, salário mínimo, salário da indústria e produtividade apresentam correlação positiva no período. Ressalta-se a forte correlação entre Salário Mínimo e 
Salário da Indústria de SP, apesar de deslocamento na trajetória, como ambos apresentaram em geral trajetória de crescimento.

\begin{tabular}{lcccc}
\hline & Produtividade & Salário Ind. SP & Salário Ind. BR & Salário Mínimo \\
\hline Produtividade & $\mathbf{1 , 0 0}$ & 0,69 & 0,03 & 0,67 \\
Salário Ind. SP & 0,69 & $\mathbf{1 , 0 0}$ & 0,59 & 0,96 \\
Salário Ind. BR & 0,03 & 0,59 & $\mathbf{1 , 0 0}$ & 0,68 \\
Salário Mínimo & 0,67 & 0,96 & 0,68 & $\mathbf{1 , 0 0}$ \\
\hline
\end{tabular}

TABELA 1 - Correlação entre Salário Mínimo Real, Salário Real Médio da Indústria de SP, Salário Real Médio da Indústria BR e Produtividade da Industria

Fonte: Elaboração própria a partir de dados do Ipeadata (2017) e IBGE-PIA (vários anos)

Em relação ao impacto do salário mínimo no custo da indústria, portanto, consideraremos em primeira instância que a trajetória estacionária da produtividade no período tende a manter constante o custo por produto da mão de obra (AMADEO apud NETTO e CURADO, 2005). Tendo isto em conta, analisaremos no Gráfico 4, além do salário mínimo real médio, a produtividade da indústria e o salário médio real da indústria, o Custo Total Industrial (CTI) e o VAB. Os dados sobre o CTI foram também extraídos da PIA-EMPRESA do IBGE e deflacionados pelo IPCA.

Ressalta-se que agora consideraremos as médias anuais das variáveis que anteriormente eram mensais, a fim de comparação com as demais varáveis da indústria que possuem disponibilidade anual. Destaca-se ainda que, o recorte temporal foi reduzido para o período entre os anos 1996 e $2015^{7}$ e que, neste momento, a base passa a ser o ano de 2000.

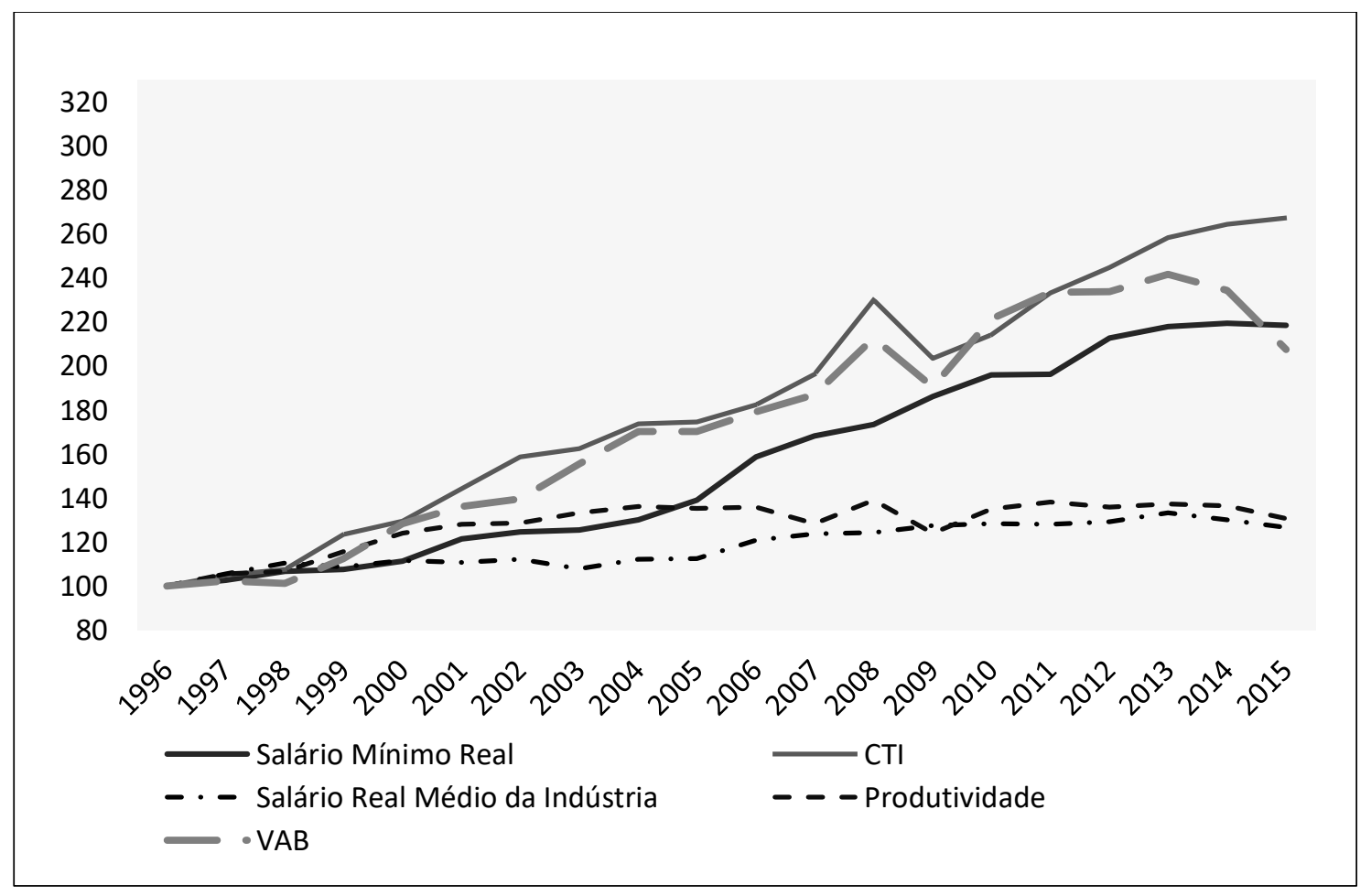

GRÁFICO 4 - Salário Mínimo Real, Produtividade da Industria, Custo Total das Atividades Industriais (CTI), Valor Agregado Bruto (VAB) e Salário Real Médio da Indústria, anual, de 1996 a 2015 (1996=100)

Fonte: Elaboração própria a partir de dados do Ipeadata (2017) e IBGE-PIA (vários anos)

Inicialmente ao analisar o custo total da indústria no período, notam-se dois fenômenos passíveis de análise: i) O primeiro relaciona-se ao comportamento apresentado pelo custo da indústria

\footnotetext{
${ }^{7}$ Dada a disponibilidade de dados da PIA-EMPRESA do IBGE
} 
em relação ao salário mínimo: excluindo-se os anos de 2008 e 2009, os dois índices apresentam trajetórias semelhantes (Gráfico 4); ii) Observa-se, contudo, que o CTI real guarda relações muito estreitas mais com o VAB do que com a produtividade e o Salário Real médio Industrial com correlações de $0,98,0,78$ e 0,93 .

Dessa forma, o crescimento do CTI no período é tanto acima do Salário Mínimo quanto do Salário médio da Indústria de modo que a razão entre os índices de Salário Mínimo e Salário da Indústria sobre o CTI é de 0,82 e 0,47, respectivamente, em 2016. Assim, é improvável que o crescimento médio anual dos salários industriais de 1,26\% seja determinante para o aumento dos custos industriais, 5,31\% anuais em todo o período. Em tempo, o aumento médio da produtividade no período $(1,42 \%$ ao ano) foi ainda superior ao crescimento dos salários da indústria, e é possível supor que tal acréscimo mais do que proporcional na produtividade causa uma redução no custo da indústria em função de salários (AMADEO apud NETTO e CURADO, 2005).

Assim sendo, não é possível inferir que aumentos reais constantes do salário mínimo causam aumentos diretos no custo da indústria através dos salários industriais. Somado a isso, pode-se considerar o argumento de que o aumento de produtividade no período pode compensar o aumento de outros custos ao reduzir o custo de capital humano por produto (AMADEO apud NETTO e CURADO, 2005). A discrepância entre VAB e CTI observada a partir de 2012 não ocorre concomitante à uma redução da produtividade ou a aumentos nos salários industriais. Antes, Nos anos de 2014 e 2015 se verifica uma redução nos salário mínimo real e no salário médio industrial.

\begin{tabular}{cccccc}
\hline Ano & Salários/Lucro & Salários/CTI & Salários/VAB & Lucro/CTI & Lucro/Receita \\
\hline 1996 & 100,00 & 100,00 & 100,00 & 100,00 & 100,00 \\
1997 & 116,37 & 95,63 & 97,86 & 82,18 & 82,73 \\
1998 & 187,15 & 91,79 & 97,34 & 49,05 & 49,99 \\
1999 & 559,63 & 74,11 & 81,34 & 13,24 & 13,68 \\
2000 & 51,23 & 73,95 & 74,69 & 144,36 & 142,02 \\
2001 & 60,42 & 68,86 & 72,96 & 113,97 & 113,38 \\
2002 & 178,66 & 60,50 & 68,75 & 33,87 & 34,72 \\
2003 & 26,85 & 64,77 & 67,67 & 241,23 & 229,22 \\
2004 & 27,38 & 64,67 & 66,00 & 236,22 & 224,85 \\
2005 & 24,88 & 67,18 & 68,97 & 270,04 & 254,02 \\
2006 & 24,92 & 69,68 & 70,94 & 279,66 & 262,18 \\
2007 & 24,72 & 69,61 & 73,01 & 281,57 & 263,79 \\
2008 & 40,35 & 64,77 & 70,08 & 160,53 & 157,00 \\
2009 & 25,87 & 75,08 & 80,21 & 290,20 & 271,07 \\
2010 & 25,85 & 77,77 & 75,20 & 300,89 & 280,02 \\
2011 & 31,26 & 75,11 & 75,03 & 240,23 & 228,35 \\
2012 & 47,38 & 75,92 & 79,44 & 160,23 & 156,73 \\
2013 & 52,79 & 75,11 & 80,27 & 142,27 & 140,08 \\
2014 & 140,76 & 73,91 & 83,45 & 52,51 & 53,45 \\
2015 & $-86,24$ & 67,96 & 87,56 & $-78,81$ & $-84,41$ \\
\hline Média & $\mathbf{8 3 , 0 1}$ & $\mathbf{7 4 , 3 2}$ & $\mathbf{7 8 , 5 4}$ & $\mathbf{1 5 5 , 6 7}$ & $\mathbf{1 4 8 , 6 4}$ \\
\hline
\end{tabular}

Tabela 2 -Índices da participação dos Salários Industriais no Lucro, Custo e VAB da Indústria e da participação dos Lucros nos Custos e nas Receitas Industriais, anual, de 1996 a 2015 (1996=100)

Fonte: Elaboração própria a partir de dados do IBGE (vários anos)

Por fim, foram calculados índices que busquem captar o conflito distributivo no período. Para tanto foram considerados, de forma complementar, os dados de Receita Total (RT) e Salários da PIAEMPRESA, deflacionados pelo IPCA. O Lucro Bruto foi calculado a partir da diferença entre RT e 
CTI. Foram calculados índices que medem a participação dos salários nos lucros, nos custos e no VAB, bem como a participação do Lucro no VAB e na RT.

A partir disso, verifica-se que o aumento do custo total da indústria não significou necessariamente aumento no custo médio de produção ou diminuição da parcela de lucro. Do contrário, na Tabela 1 é possível verificar que o crescimento do custo total esteve atrelado ao aumento das relações entre lucro e custo total e entre lucro e receita total. Além disso, a participação dos salários nos lucros, nos custos totais e no VAB caiu.

Destaca-se que entre os anos de 2005 e 2015, no qual o salário industrial total obteve acréscimos anuais de 2,45\% em média ao ano, a média do índice de relação entre os salários e o CTI foi de 72,01, abaixo da média da série total.

Respeitadas as limitações de espaço e objetivo do trabalho, não se propõe aqui uma investigação mais ampla acerca do impacto do salário mínimo na inflação por outras vias, bem como destes nos outros custos do setor industrial, salientando, no entanto, a necessidade de maior investigação dos efeitos do salário mínimo na dinâmica econômica, dado que esta constitui uma importante variável na condução da economia.

Posto isso, e considerando que o crescimento no custo total da indústria no período de aumentos reais sucessivos do salário mínimo não se dá em função do impacto do salário mínimo no nível salarial da indústria, torna-se plausível aceitar que o aumento do custo total da indústria advém de fatores externos aos determinantes do salário industrial. Isto é, efeitos na piora das expectativas empresariais em relação à diminuição da participação do lucro na produção, no aumento dos preços relativos de bens e serviços demandados pela indústria, na taxa de inflação, e consequentemente, em uma condução mais restritiva da política monetária.

\section{CONSIDERAÇÕES FINAIS}

Verifica-se tendência crescente de dispersão entre os valores reais do salário mínimo institucional e o salário médio da economia. Além disso, é constatada a existência de correlação entre o aumento do salário mínimo e a elevação do nível de preços, sobretudo do setor de serviços. Nessa perspectiva, o salário mínimo passa a ter interferência indireta na condução da política monetária, tornando-a mais restrita a uma condição de controle de preços.

Contudo, se verifica diminuta relação positiva entre salário mínimo e salário real da indústria. Portanto, conclui-se que a influência da política de aumentos sucessivos reais no salário mínimo nos preços não se realiza através de elevação dos custos de mão de obra da indústria. Entretanto, ainda assim observa-se contraproducente aumento no custo total das atividades industriais, mesmo em uma situação de produtividade não declinante. $\mathrm{O}$ aumento nos custos, entretanto, não se verificou nem como redução da taxa de lucro nem como aumento na participação dos salários nos lucros. Antes, não foram encontradas evidências que corroborem a afirmação de que aumentos sucessivos reais do salário mínimo alterem a capacidade de inversão da indústria.

Por fim, as decisões acerca da política de condução do salário mínimo institucional se mostram relevantes para a dinâmica da estrutura produtiva e social brasileira. Logo, tornam-se necessárias maiores investigações a respeito dos fatores que evidenciam a propagação dos aumentos do salário mínimo para o nível de preços, de modo a buscar, a política salarial adequada para que o desenvolvimentismo volte a lograr-se como modelo de crescimento econômico do país.

\section{REFERÊNCIAS BIBLIOGRÁFICAS}

BIELSCHOWSKY, R. (2012). Estratégia de desenvolvimento e as três frentes de expansão no Brasil: um desenho conceitual. Economia e Sociedade, v. 21, Número Especial, p. 729-747, dez.

BRESSER-PEREIRA (2004). Novo-desenvolvimentismo. Folha de S. Paulo, 19 set.

(2007). Estado y mercado en el nuevo desarrollismo. Nueva Sociedad, n. 210, p. 110125, Jul./Ago. 2007. 
(2010). Macroeconomia estruturalista do desenvolvimento. Revista de Economia Política, v. 30, n. 4: 663-686.

(2016). Reflexões sobre o Novo Desenvolvimentismo e o Desenvolvimentismo Clássico. Revista de Economia Política, vol. 36, n 2, p. 237-265.

DIEESE (2018). Política de valorização do Salário Mínimo. Nota técnica, n. 188. Dísponivel em < https://www.dieese.org.br/notatecnica/2018/notaTec188SalarioMinimo.pdf > Acesso em: $28 / 05 / 2018$

FIESP (maio/2015). Perda de Participação da Indústria de Transformação no PIB. Departamento de Pesquisas e Estudos Econômicos. < Disponível em: http://az545403.vo.msecnd.net/uploads/2015/05/perda-de-participacao-da-industria-no-pib.pdf > Acesso: 28/06/2017

FILGUEIRAS, L. (2012) A natureza do atual padrão de desenvolvimento brasileiro e o processo de desindustrialização. Relatório de Pesquisa. Centro Celso Furtado, Rio de Janeiro.

MARTINEZ, T. S.; BRAGA, J. M. (2012). Crescimento liderado pelos salários, política monetária e inflação no Brasil. V Encontro Internacional da Associação Keynesiana Brasileira: São Paulo. Disponível em: <http://www.akb.org.br/upload/130820121621498835_Martinez\%20e\%20Braga.pdf> Acesso: $27 / 06 / 2017$

MEDEIROS, C. A. (2015) A Influência do salário mínimo sobre a taxa de salários no Brasil na última década. Economia \& Sociedade, v. 24, p. 263-292.

MOLLO, M.L.R. e AMADO, A. (2015) O debate desenvolvimentista no Brasil: tomando partido. Economia e Sociedade, Campinas, v. 24, n. 1 (53), p. 1-28, abr. Disponível em < http://www.scielo.br/pdf/ecos/v24n1/0104-0618- ecos-24- 01-00001.pdf > Acesso em 29/06/2017.

MOLLO, M.L.R. e FONSECA, P.C.D. (2013) Desenvolvimentismo e Novo-Desenvolvimentismo: raízes teóricas e precisões conceituais. REP, vol. 33, p. 222-239, abril-junho. Disponível em < http://www.rep.org.br/PDF/131-2.PDF> Acesso em 30/06/2017.

NETTO, C. R. de S.; CURADO, M. L. (2005). Produtividade do trabalho, salários reais e desemprego na indústria de transformação do Brasil na década de 1990: teoria e evidência. Revista Economia Contemporânea, Rio de Janeiro, v.9, n.3, p. 485-508. Disponível em <http://dx.doi.org/10.1590/S1415-98482005000300002> acesso em 27/06/2017

OREIRO, J. L. C. (2012) Wage-led versus export-led: desfazendo confusões conceituais. Macroeconomia Estruturalista do Desenvolvimento. Disponível em < https://jlcoreiro.wordpress.com/2012/09/24/wage-led-versus-export-led-desfasendo-confusoesconceituais/> acesso em 01/07/2017

(2012). Novo-Desenvolvimentismo, Crescimento Econômico e Regimes de Política Macroeconômica. Estudos Avançados, v. 26, n.75, p. 29-40.

SANTOS, P. L. (2013) Production and consumption credit in a continuous-time model of the circuit of Capital. Historical Materialism, v. 17, n. 2, p. 180. 
SCHLABITZ, C. J. (2014). A Economia Política do Salário Mínimo. Tese de doutorado. UFRGS, Porto Alegre.

SICSÚ, J.; PAULA, L. F.; MICHEL, R. (2005) Introdução. In: Novo desenvolvimentismo: um projeto nacional de crescimento com equidade social. Barueri-SP: Manole; Rio de Janeiro: Fundação Konrad Adenauer.

SUMMA, R. F. (2015) Mercado de trabalho e a evolução dos salários no Brasil. Revista da Sociedade Brasileira de Economia Política, v. 42, p. 10-25.

TAKASAGO, M.; GUILHOTO, J.; MOLLO, M. L. R. (2017) O debate desenvolvimentista no Brasil: discutindo resultados da matriz de insumo-produto. Planejamento e Políticas Públicas, $\mathrm{n}$. 48, p 385-409. 